\title{
DIREITO E DEMOCRACIA E O PAPEL DO ENSINO JURÍDICO
}

\section{LAW AND DEMOCRACY AND THE ROLE OF LEGAL EDUCATION}

\author{
MARCO AURÉLIO MELLO ${ }^{1}$
}

Resumo: Este artigo tem como objeto a relação Direito e democracia, considerados o constitucionalismo e a atuação do Judiciário, bem como a importância do ensino jurídico para a solução de conflitos que venham a surgir. Na primeira parte, é apresentado o conceito de democracia. Na segunda, discorrese sobre a relação com o Direito à luz da ideia de constitucionalismo e da jurisdição constitucional. Na terceira, é examinado o papel do ensino jurídico, e, particularmente, da Faculdade Nacional de Direito, na formação de profissionais e cidadãos comprometidos com os valores preconizados pela Lei Maior.

Palavras-Chave: Direito; Democracia; Constitucionalismo; Educação.

ABstract: This article has as its object the relationship between Law and democracy, considering the constitutionalism and the role of the Judiciary, as well as the importance of legal education for the solution of conflicts that may arise. In the first part, the concept of democracy is present. In the second part, the relationship with the Law is discussed in light of the idea of constitutionalism and constitutional jurisdiction. In the third, the role of legal education, and particularly of the National Faculty of Law, in the training of professionals and citizens committed to the values advocated by Major Law is examined.

KeYwORDS: Law; Democracy; Constitutionalism; Education.

\footnotetext{
${ }^{1}$ Ex-ministro do Supremo Tribunal Federal. Bacharel em Ciências Jurídicas e Sociais pela Faculdade de Direito da Universidade Federal do Rio de Janeiro, concluído em 1973. Mestrado em Direito Privado pela Faculdade de Direito da Universidade Federal do Rio de Janeiro. Certificado de capacitação obtido em 1982.
} 


\section{INTRODUÇÃO}

O professor Carlos Bolonha honrou-me com o convite para participar de dossiê da Revista Estudos Institucionais - REI, em comemoração dos 130 anos da Faculdade Nacional de Direito da Universidade Federal do Rio de Janeiro.

Não poderia iniciar sem, antes, fazer registro quanto à homenageada, a instituição em que me formei e depois logrei capacitação no curso de mestrado. Valho-me sempre das lições aprendidas naqueles bancos. Tive grandes professores, como Celso César Papaléo, Celso de Albuquerque Mello, Cotrim Neto, Hélio Tornaghi, Machado Paupério, Pedro Calmon, Regina Gondim, entre tantos outros.

O texto tem a seguinte estrutura: no próximo tópico, são apresentados conceitos de democracia; subsequentemente, examina-se a relação com o Direito à luz da ideia de constitucionalismo e da jurisdição constitucional; após, é analisada a importância do ensino jurídico, com ênfase no oferecido pela Faculdade Nacional de Direito, direcionado à formação de profissionais e cidadãos comprometidos com valores da Lei Maior; alfim, breve conclusão.

\section{O QUE É DEMOCRACIA?}

Democracia não é apenas o regime político mais adequado entre tantos outros.

É direito do cidadão, fundado nos valores da soberania popular e do autogoverno. A variedade de modelos sinaliza critérios para um país ser considerado democrático.

De acordo com Charles Tilly², tem-se democracia constitucional, substancial, procedimental e orientada ao processo. $\mathrm{O}$ primeiro tipo encerra as leis promulgadas por um regime em relação à atividade política. $\mathrm{O}$ foco são as formas constitucionais e os arranjos legais. A concepção substancial relaciona-se aos contextos sociais e políticos - bem-estar humano, liberdade individual, segurança, igualdade social, deliberação pública e resolução pacífica de conflitos. O critério procedimental remete às eleições, no que garantida alternância de governos e políticas. A definição alusiva ao processo político parte da premissa segundo a qual este somente adquire características democráticas quando assegurados a todos pressupostos materiais para atuarem na tomada de decisões a impactarem a comunidade. Nesse sentido, democracia implica serem os cidadãos tratados como politicamente iguais.

Ao identificar o caráter democrático do processo político, Tilly serviu-se dos cinco parâmetros tidos por Robert $\mathrm{Dahl}^{3}$ como imprescindíveis à satisfação das exigências em relação ao direito à igual participação nas decisões relevantes de certa comunidade:

\footnotetext{
2 TILLY, Charles. Democracy. New York: Cambridge University Press, 2007. p. 7-8.

${ }^{3}$ DAHL, Robert. On democracy. New Haven: Yale University Press, 1996.
} 
1) Participação efetiva - igual e efetiva oportunidade para todos apresentarem aos demais participantes as próprias percepções, antes de uma política ser adotada;

2) Igualdade de voto - igual e efetiva oportunidade para todos votarem e terem o próprio voto contado no momento da tomada de decisão política;

3) Conhecimento esclarecido - igual e efetiva oportunidade para todos aprenderem a respeito de políticas alternativas relevantes e consequências prováveis das medidas a serem tomadas, dentro de limites razoáveis de tempo;

4) Controle da agenda - igual e efetiva viabilização para todos decidirem questões a serem inseridas na agenda política, de modo a assegurar-se a possibilidade de alteração nas pautas temáticas;

5) Inclusão de adultos - igual e efetiva garantia, à maioria dos adultos residentes na comunidade, de plenos direitos da cidadania, nos quais inseridos os quatro critérios anteriores, o que vem a ser condição inafastável para tratamento igualitário dos integrantes da comunidade.

A igualdade política reduz à medida que esses critérios são inobservados. Visando evitar desvios, é necessário mecanismo voltado a incentivar e assegurar a participação nos assuntos de governo.

Nada obstante ser conceito ideal, difícil de ser alcançado na plenitude, não cabe desconsiderar os parâmetros mencionados. Têm grande valor, no que revelam balizas para a formulação de desenhos constitucionais, arranjos institucionais e sistemas políticos que se almeje democráticos.

O poder é exercido indiretamente pelos cidadãos, e considerados os representantes eleitos. A tomada de decisões políticas - como a elaboração de leis - , na via direta, é inviável nas sociedades plurais e complexas da atualidade. A soberania popular não assume papel autoral, mas legitimador da atuação dos representantes escolhidos.

A igual participação política também se encontra no centro da democracia deliberativa. A deliberação pública racionaliza e legitima as decisões tomadas no âmbito dos processos políticos e de gestão, evitando o amesquinhamento e a manipulação. Para alcançar-se a legitimidade, há de ocorrer em contexto aberto, livre e igualitário, ou seja, todos devem participar, sem qualquer tipo de coerção física ou moral, em igualdade de condições relativamente às possibilidades e capacidades para influenciar e persuadir.

A oportunidade de atuação política configura pressuposto de uma deliberação justa e eficiente. Na perspectiva procedimental da democracia deliberativa, as decisões devem ser mantidas abertas no tocante ao conteúdo dos resultados, mas limitadas pela observância dos princípios a assegurarem condições 
procedimentais de legitimidade, voltados à garantia da participação equânime na deliberação pública.

A igualdade de acesso à participação surge como requisito conceitual e empírico da democracia, tanto sob a óptica representativa, quanto sob a deliberativa. Ideal a ser sempre buscado, acaba revelando-se princípio de governo a homenagear a capacidade e a autonomia do cidadão em decidir.

\section{DIREITO E DEMOCRACIA}

O Direito é criado por um processo político. Semelhante ao que ocorre com as leis, uma assembleia delibera e promulga uma Constituição, a qual se prolonga no tempo por meio de arranjos institucionais mediante os quais alcançada a estabilidade. A democracia, por sua vez, é viabilizada e concretizada mediante regras e procedimentos, mantendo relação direta com o autogoverno coletivo.

A compreensão do vínculo existente entre os dois conceitos requer o exame da tensão que se verifica considerados constitucionalismo e democracia. Esta diz respeito ao governo da maioria, ao passo que aquele guarda relação com a ideia, liberal, de contenção do poder - e, por consequência, da soberania popular visando a liberdade dos governados. ${ }^{4}$

$\mathrm{O}$ excesso na dose de constitucionalismo pode asfixiar a vontade do povo, inviabilizando a autonomia pública. Em países nos quais previsto o controle jurisdicional de constitucionalidade das leis, surgem bloqueios à deliberação coletiva, sendo subtraídas, pelo constituinte originário, dos representantes do povo, discussões sobre determinados temas. Exemplo desse fenômeno são as cláusulas pétreas contidas na Constituição da República Federativa do Brasil. A teor do artigo 60, $\S 4^{\circ}$, é proibida a abolição da forma federativa de Estado, do voto direto, secreto, universal e periódico, da separação de poderes e dos direitos e garantias fundamentais.

Eventual democracia sem limites coloca em risco os direitos fundamentais de minorias e outros requisitos essenciais do jogo político. ${ }^{5}$

O Judiciário, integrado por agentes não eleitos, ao aplicar as normas surgidas do processo democrático, conforma a vontade popular e invalida atos conflitantes com a Constituição, surgindo a chamada dificuldade contramajoritária ${ }^{6}$.

O Direito, considerada a Lei Maior, criado pela política, deve ser desta separado, sob risco de deslegitimar-se a atuação do Judiciário. Faz-se necessário definir até onde pode uma Constituição retirar do povo decisões sobre o próprio

\footnotetext{
${ }^{4}$ SARMENTO, Daniel. Direito adquirido, emenda constitucional, democracia e justiça social. Revista Eletrônica sobre a Reforma do Estado (RERE), Salvador, Instituto Brasileiro de Direito Público, n. 12, p. 3-4, dez./jan./fev. 2008. Disponível em: http://www.direitodoestado.com.br/codrevista.asp?cod=248. Acesso em: 5 jul. 2021.

${ }^{5}$ Idem, ibidem, p. 4.

${ }^{6}$ BICKEL, Alexander M. The least dangerous branch: the Supreme Court at the bar of politics. Indianapolis: Bobbs-Merrill, 1962.
} 
futuro, vinculando gerações ao estabelecido quando da elaboração. Cabe indagar: Não seria uma forma de governo dos mortos sobre os vivos?

Há interessante metáfora a justificar um regime constitucional. ${ }^{7}$ A partir do episódio protagonizado por Ulisses e as sereias, narrado por Homero no livro XII da Odisseia, compara-se a ideia de constituição a um pré-compromisso, análogo ao firmado pelo herói grego, o qual, desejoso de ouvir a canção daqueles seres mitológicos, determinou à tripulação que tampassem com cera os ouvidos e o amarrassem ao mastro do navio, proibindo-os de retirar-lhe as amarras. Limitou, assim, o poder da vontade que teria no futuro e evitou a morte. $\mathrm{O}$ mesmo ocorre com as constituições, por meio das quais restringido o espaço de deliberação das maiorias de plantão, impedindo-se a sucumbência coletiva em virtude das próprias paixões e fraquezas momentâneas.

A comparação faz mais sentido quando remetida aos limites materiais ao poder de reforma, somente superáveis ante a emergência de um novo poder constituinte originário. ${ }^{8}$ No tocante à legitimidade das continências impostas à democracia, há, ainda, o núcleo essencial, considerados os valores encerrados na Lei Maior, sem o qual surgiria desfigurado o projeto de 1988.

Eventual leitura ampliativa das cláusulas pétreas pode implicar engessamento da democracia. Se juízes fizerem cálculos políticos, consequencialistas, ou tentarem impor a própria moral, destoando do que previsto no texto, contaminam a atividade judicante - e, por extensão, o Direito. Põe-se em dúvida a legitimidade do Judiciário, no que feita a nomeação para os cargos sem prévia eleição e exercidas as funções de forma vitalícia, garantidas a inamovibilidade e a irredutibilidade de subsídios. O Direito, portanto, é fruto da política, mas deve buscar desligar-se dela.

Exige-se autocontenção e prudência do magistrado ao interferir em decisões dos Poderes eleitos. Nem todas as controvérsias envolvendo a Constituição são passíveis de solução no Judiciário. Há zona de interpretação e conflito subjacente, a pressupor atuação dos demais Poderes. ${ }^{9}$ Não se vislumbra rever na Justiça o resultado de processo jurídico-político de impedimento de presidente. Também não cabe conceber a criação e execução, pelo Supremo, de políticas públicas.

\footnotetext{
7 ELSTER, Jon. Ulysses and the sirens. Cambridge: Cambridge University Press, 1979.

${ }^{8}$ Pode-se cogitar, como sustenta Jorge Miranda da "dupla revisão", ou seja, a revogação da cláusula constitucional a versar a proibição - no caso da Constituição de 1988, a supressão, pelo constituinte derivado, do artigo $60, \S 4^{\circ}-\mathrm{e}$, em seguida, do dispositivo cuja alteração era antes vedada. Penso ser espécie de fraude, uma vez ter-se tentativa, do Legislativo, de burlar a proibição instituída pelo constituinte originário. (MIRANDA, Jorge. Teoria do estado e da constituição. Rio de Janeiro: Forense, 2003. p. 413.)

9 SAGER, Lawrence G. Justice in plainclothes: a theory of American constitutional practice. New Haven: Yale University Press, 2004.
} 
Viável é a salvaguarda, pelo Judiciário, dos direitos mínimos essenciais à democracia ${ }^{10}$ : direitos individuais liberais clássicos (liberdade de consciência, de expressão etc.), igualdade participativa, educação, saúde, acesso à informação. Faz-se legítima, ainda, a jurisdição constitucional quando, uma vez provocada, estiverem em jogo direitos fundamentais de minorias inobservados ante omissão dos Poderes políticos.

Foi o que motivou o implemento de medidas acauteladoras nas arguições de descumprimento de preceito fundamental no 347, de minha relatoria, e 709, relator ministro Luís Roberto Barroso. Naquela, declarou-se o estado de coisas inconstitucional do sistema penitenciário, enquanto, nesta, reconheceu-se a omissão do Executivo na formulação e execução de políticas públicas voltadas à proteção de índios contra os efeitos da pandemia covid-19.

Em 12 de abril de 2012, ao apreciar a arguição de descumprimento de preceito fundamental $\mathrm{n}^{\mathrm{o}}$ 54, de minha relatoria, o Colegiado Maior assentou não configurar crime a interrupção da gravidez de fetos anencéfalos. A inconstitucionalidade da interpretação dos artigos 124, 126 e 128 do Código Penal, no sentido da tipicidade da conduta, decorreu da observância direta do princípio da dignidade da pessoa humana e dos direitos da mulher à saúde, à autodeterminação, à liberdade sexual e reprodutiva. O Supremo proclamou implicar ofensa à dignidade e à autonomia obrigá-la a conduzir até o fim gestação de feto anencéfalo. Em meu voto, afastada a possibilidade de a questão "ser examinada sob os influxos de orientações morais religiosas" e afirmada a antítese entre anencefalia e vida, exteriorizei estarem em debate apenas direitos de gestantes de natimorto cerebral - "a privacidade, a autonomia e a dignidade humana dessas mulheres”. Em síntese:

\begin{abstract}
A imposição estatal da manutenção de gravidez cujo resultado final será irremediavelmente a morte do feto vai de encontro aos princípios basilares do sistema constitucional, mais precisamente à dignidade da pessoa humana, à liberdade, à autodeterminação, à saúde, ao direito de privacidade, ao reconhecimento pleno dos direitos sexuais e reprodutivos de milhares de mulheres. $\mathrm{O}$ ato de obrigar a mulher a manter a gestação, colocando-a em uma espécie de cárcere privado em seu próprio corpo, desprovida do mínimo essencial de autodeterminação e liberdade, assemelha-se à tortura ou a um sacrifício que não pode ser pedido a qualquer pessoa ou dela exigido.
\end{abstract}

10 Nas palavras de Habermas, esse papel seria o de "guardião da democracia" (Direito e democracia: entre facticidade e validade. Tradução de Flávio Siebeneichler. Rio de Janeiro: Tempo Brasileiro, v. 1, 1997, p. 297). No Brasil, ver Souza Neto e Sarmento (Notas sobre jurisdição constitucional e democracia: a questão da "última palavra" e alguns parâmetros de autocontenção judicial. Quaestio Iuris, v. 6, n. 2, p. 119-161, 2013). 
Vale observar que o Pleno, tal como havia feito relativamente à união estável homoafetiva, interpretou os elementos textuais e os princípios constitucionais pertinentes a partir da evolução social e, na espécie, também na fático-tecnológica.

Os tribunais constitucionais representam avanço na melhoria dos processos institucional e civilizatório pelos quais passam as democracias. Mediante a prestação jurisdicional, os direitos são valorados e a Justiça é concretizada.

A decisão da maioria, na lição de Ronald Dworkin ${ }^{11}$, não é justa nem valiosa em si, pois não há nada que possua valor inerente quando permitido a grande número de pessoas impor, a número menor, a própria vontade. Só há valor e Justiça se algumas circunstâncias, certos limites são observados, a exemplo da igualdade entre os participantes do processo político e o respeito aos direitos fundamentais.

Ao Supremo compete proteger e garantir a efetividade do conteúdo normativo da Constituição Federal, em especial a centralidade dos direitos fundamentais. Deve buscar a estabilidade da ordem jurídica, prestigiando princípios caros aos cidadãos: democracia, liberdade, igualdade, solidariedade e segurança.

Já não se limita a interpretar por último a Carta da República. O faz por todos os juízes e tribunais do País, exigidas clareza, coerência e integridade na fixação de teses, premissas e fundamentos, de modo a orientar a máquina judiciária, uma vez ser apenas um o sentido das palavras emanadas do legislador. É preciso repetir a mais não poder a lição. A rigidez dogmática pode auxiliar nas percepções de realização da Justiça, garantindo-se a estabilidade na prestação jurisdicional.

É inegável que a Constituição sugere questionamentos filosóficos, mas é necessário racionalizá-los para que o jurisdicionado compreenda os direitos possuídos. Não significa restringir-se a interpretações estáticas da conduta social, tornando o Direito uma ciência cega. É preciso garantir-se a atualização. O Tribunal tem feito o que lhe cabe. Não fossem as decisões por si proferidas, a Constituição poderia ter falhado no propósito de materializar a democracia e assegurar direitos fundamentais.

$\mathrm{Na}$ relação dos mecanismos constitucionais com a identidade cultural brasileira, exerce papel fundamental. A influência do Judiciário na institucionalização das liberdades individuais e na preservação da estabilidade do ordenamento jurídico provoca ampla discussão e engajamento públicos. E assim o é justamente por ter a Lei Maior o centro que tem. A lógica é rica. O legislador dela fez livro de direitos, e o Supremo tem guardado papel de guardião.

Ainda há muito a realizar. Inscritas nessa engenharia, existem promessas a serem aperfeiçoadas. Nada disso, porém, leva ao descrédito da Lei Maior, uma vez ser a realização de um projeto constitucional movimento, trajetória, construção. Nenhuma constituição é obra acabada. A legitimidade depende não

${ }^{11}$ DWORKIN, Ronald. Taking rights seriously. Cambridge: Harvard University Press, 1977. 
só da qualidade do texto e do arranjo político-institucional estabelecido, mas também do empenho da sociedade. ${ }^{12}$

\section{O ENSINO JURÍdICO E A CONSTITUIÇÃO FEDERAL}

O Direito é criado por um processo político. Semelhante ao que ocorre com as leis, uma assembleia delibera e promulga uma Constituição, a qual se prolonga no tempo por meio de arranjos institucionais mediante os quais alcançada a estabilidade. A democracia, por sua vez, é viabilizada e concretizada mediante regras e procedimentos, mantendo relação direta com o autogoverno coletivo.

A compreensão do vínculo existente entre os dois conceitos requer o exame da tensão que se verifica considerados constitucionalismo e democracia. Esta diz respeito ao governo da maioria, ao passo que aquele guarda relação com a ideia, liberal, de contenção do poder - e, por consequência, da soberania popular visando a liberdade dos governados. ${ }^{13}$

O excesso na dose de constitucionalismo pode asfixiar a vontade do povo, inviabilizando a autonomia pública. Em países nos quais previsto o controle jurisdicional de constitucionalidade das leis, surgem bloqueios à deliberação coletiva, sendo subtraídas, pelo constituinte originário, dos representantes do povo, discussões sobre determinados temas. Exemplo desse fenômeno são as cláusulas pétreas contidas na Constituição da República Federativa do Brasil. A teor do artigo 60, $\S 4$, é proibida a abolição da forma federativa de Estado, do voto direto, secreto, universal e periódico, da separação de poderes e dos direitos e garantias fundamentais.

Eventual democracia sem limites coloca em risco os direitos fundamentais de minorias e outros requisitos essenciais do jogo político. ${ }^{14}$

O Judiciário, integrado por agentes não eleitos, ao aplicar as normas surgidas do processo democrático, conforma a vontade popular e invalida atos conflitantes com a Constituição, surgindo a chamada dificuldade contramajoritária ${ }^{15}$.

O Direito, considerada a Lei Maior, criado pela política, deve ser desta separado, sob risco de deslegitimar-se a atuação do Judiciário. Faz-se necessário definir até onde pode uma Constituição retirar do povo decisões sobre o próprio futuro, vinculando gerações ao estabelecido quando da elaboração. Cabe indagar: Não seria uma forma de governo dos mortos sobre os vivos?

${ }^{12}$ BALKIN, Jack M. Constitutional redemption: political faith in an unjust world. Cambridge: Harvard University Press, 2011. p. 8-16.

${ }^{13}$ SARMENTO, Daniel. Direito adquirido, emenda constitucional, democracia e justiça social. Revista Eletrônica sobre a Reforma do Estado (RERE), Salvador, Instituto Brasileiro de Direito Público, n. 12, p. 3-4, dez./jan./fev. 2008. Disponível em: http://www.direitodoestado.com.br/codrevista.asp?cod=248. Acesso em: 5 jul. 2021.

${ }^{14}$ Idem, ibidem, p. 4.

${ }^{15}$ BICKEL, Alexander M. The least dangerous branch: the Supreme Court at the bar of politics. Indianapolis: Bobbs-Merrill, 1962. 
Há interessante metáfora a justificar um regime constitucional ${ }^{16}$. A partir do episódio protagonizado por Ulisses e as sereias, narrado por Homero no livro XII da Odisseia, compara-se a ideia de constituição a um pré-compromisso, análogo ao firmado pelo herói grego, o qual, desejoso de ouvir a canção daqueles seres mitológicos, determinou à tripulação que tampassem com cera os ouvidos e o amarrassem ao mastro do navio, proibindo-os de retirar-lhe as amarras. Limitou, assim, o poder da vontade que teria no futuro e evitou a morte. O mesmo ocorre com as constituições, por meio das quais restringido o espaço de deliberação das maiorias de plantão, impedindo-se a sucumbência coletiva em virtude das próprias paixões e fraquezas momentâneas.

A comparação faz mais sentido quando remetida aos limites materiais ao poder de reforma, somente superáveis ante a emergência de um novo poder constituinte originário ${ }^{17}$. No tocante à legitimidade das continências impostas à democracia, há, ainda, o núcleo essencial, considerados os valores encerrados na Lei Maior, sem o qual surgiria desfigurado o projeto de 1988.

Eventual leitura ampliativa das cláusulas pétreas pode implicar engessamento da democracia. Se juízes fizerem cálculos políticos, consequencialistas, ou tentarem impor a própria moral, destoando do que previsto no texto, contaminam a atividade judicante - e, por extensão, o Direito. Põe-se em dúvida a legitimidade do Judiciário, no que feita a nomeação para os cargos sem prévia eleição e exercidas as funções de forma vitalícia, garantidas a inamovibilidade e a irredutibilidade de subsídios. O Direito, portanto, é fruto da política, mas deve buscar desligar-se dela.

Exige-se autocontenção e prudência do magistrado ao interferir em decisões dos Poderes eleitos. Nem todas as controvérsias envolvendo a Constituição são passíveis de solução no Judiciário. Há zona de interpretação e conflito subjacente, a pressupor atuação dos demais Poderes. ${ }^{18}$ Não se vislumbra rever na Justiça o resultado de processo jurídico-político de impedimento de presidente. Também não cabe conceber a criação e execução, pelo Supremo, de políticas públicas.

Viável é a salvaguarda, pelo Judiciário, dos direitos mínimos essenciais à democracia ${ }^{19}$ : direitos individuais liberais clássicos (liberdade de consciência, de

16 ELSTER, Jon. Ulysses and the sirens. Cambridge: Cambridge University Press, 1979.

${ }^{17}$ Pode-se cogitar, como sustenta Jorge Miranda da "dupla revisão", ou seja, a revogação da cláusula constitucional a versar a proibição - no caso da Constituição de 1988, a supressão, pelo constituinte derivado, do artigo $60, \S 4^{\circ}-\mathrm{e}$, em seguida, do dispositivo cuja alteração era antes vedada. Penso ser espécie de fraude, uma vez ter-se tentativa, do Legislativo, de burlar a proibição instituída pelo constituinte originário. (MIRANDA, Jorge. Teoria do estado e da constituição. Rio de Janeiro: Forense, 2003. p. 413.)

18 SAGER, Lawrence G. Justice in plainclothes: a theory of American constitutional practice. New Haven: Yale University Press, 2004.

${ }^{19}$ Nas palavras de Habermas, esse papel seria o de "guardião da democracia" (Direito e democracia: entre facticidade e validade. Tradução de Flávio Siebeneichler. Rio de Janeiro: Tempo Brasileiro, v. 1, 1997, p. 297). No Brasil, ver Souza Neto e Sarmento (Notas sobre 
expressão etc.), igualdade participativa, educação, saúde, acesso à informação. Faz-se legítima, ainda, a jurisdição constitucional quando, uma vez provocada, estiverem em jogo direitos fundamentais de minorias inobservados ante omissão dos Poderes políticos.

Foi o que motivou o implemento de medidas acauteladoras nas arguições de descumprimento de preceito fundamental $n^{\circ} 347$, de minha relatoria, e 709, relator ministro Luís Roberto Barroso. Naquela, declarou-se o estado de coisas inconstitucional do sistema penitenciário, enquanto, nesta, reconheceu-se a omissão do Executivo na formulação e execução de políticas públicas voltadas à proteção de índios contra os efeitos da pandemia covid-19.

Em 12 de abril de 2012, ao apreciar a arguição de descumprimento de preceito fundamental $\mathrm{n}^{\mathrm{o}}$ 54, de minha relatoria, o Colegiado Maior assentou não configurar crime a interrupção da gravidez de fetos anencéfalos. A inconstitucionalidade da interpretação dos artigos 124, 126 e 128 do Código Penal, no sentido da tipicidade da conduta, decorreu da observância direta do princípio da dignidade da pessoa humana e dos direitos da mulher à saúde, à autodeterminação, à liberdade sexual e reprodutiva. O Supremo proclamou implicar ofensa à dignidade e à autonomia obrigá-la a conduzir até o fim gestação de feto anencéfalo. Em meu voto, afastada a possibilidade de a questão "ser examinada sob os influxos de orientações morais religiosas" e afirmada a antítese entre anencefalia e vida, exteriorizei estarem em debate apenas direitos de gestantes de natimorto cerebral - "a privacidade, a autonomia e a dignidade humana dessas mulheres". Em síntese:

A imposição estatal da manutenção de gravidez cujo resultado final será irremediavelmente a morte do feto vai de encontro aos princípios basilares do sistema constitucional, mais precisamente à dignidade da pessoa humana, à liberdade, à autodeterminação, à saúde, ao direito de privacidade, ao reconhecimento pleno dos direitos sexuais e reprodutivos de milhares de mulheres. $\mathrm{O}$ ato de obrigar a mulher a manter a gestação, colocando-a em uma espécie de cárcere privado em seu próprio corpo, desprovida do mínimo essencial de autodeterminação e liberdade, assemelha-se à tortura ou a um sacrifício que não pode ser pedido a qualquer pessoa ou dela exigido.

Vale observar que o Pleno, tal como havia feito relativamente à união estável homoafetiva, interpretou os elementos textuais e os princípios constitucionais pertinentes a partir da evolução social e, na espécie, também na fático-tecnológica.

jurisdição constitucional e democracia: a questão da "última palavra" e alguns parâmetros de autocontenção judicial. Quaestio Iuris, v. 6, n. 2, p. 119-161, 2013). 
Os tribunais constitucionais representam avanço na melhoria dos processos institucional e civilizatório pelos quais passam as democracias. Mediante a prestação jurisdicional, os direitos são valorados e a Justiça é concretizada.

A decisão da maioria, na lição de Ronald Dworkin ${ }^{20}$, não é justa nem valiosa em si, pois não há nada que possua valor inerente quando permitido a grande número de pessoas impor, a número menor, a própria vontade. Só há valor e Justiça se algumas circunstâncias, certos limites são observados, a exemplo da igualdade entre os participantes do processo político e o respeito aos direitos fundamentais.

Ao Supremo compete proteger e garantir a efetividade do conteúdo normativo da Constituição Federal, em especial a centralidade dos direitos fundamentais. Deve buscar a estabilidade da ordem jurídica, prestigiando princípios caros aos cidadãos: democracia, liberdade, igualdade, solidariedade e segurança.

Já não se limita a interpretar por último a Carta da República. O faz por todos os juízes e tribunais do País, exigidas clareza, coerência e integridade na fixação de teses, premissas e fundamentos, de modo a orientar a máquina judiciária, uma vez ser apenas um o sentido das palavras emanadas do legislador. É preciso repetir a mais não poder a lição. A rigidez dogmática pode auxiliar nas percepções de realização da Justiça, garantindo-se a estabilidade na prestação jurisdicional.

É inegável que a Constituição sugere questionamentos filosóficos, mas é necessário racionalizá-los para que o jurisdicionado compreenda os direitos possuídos. Não significa restringir-se a interpretações estáticas da conduta social, tornando o Direito uma ciência cega. É preciso garantir-se a atualização. O Tribunal tem feito o que lhe cabe. Não fossem as decisões por si proferidas, a Constituição poderia ter falhado no propósito de materializar a democracia e assegurar direitos fundamentais.

$\mathrm{Na}$ relação dos mecanismos constitucionais com a identidade cultural brasileira, exerce papel fundamental. A influência do Judiciário na institucionalização das liberdades individuais e na preservação da estabilidade do ordenamento jurídico provoca ampla discussão e engajamento públicos. E assim o é justamente por ter a Lei Maior o centro que tem. A lógica é rica. O legislador dela fez livro de direitos, e o Supremo tem guardado papel de guardião.

Ainda há muito a realizar. Inscritas nessa engenharia, existem promessas a serem aperfeiçoadas. Nada disso, porém, leva ao descrédito da Lei Maior, uma vez ser a realização de um projeto constitucional movimento, trajetória, construção. Nenhuma constituição é obra acabada. A legitimidade depende não só da qualidade do texto e do arranjo político-institucional estabelecido, mas também do empenho da sociedade. ${ }^{21}$

${ }^{20}$ DWORKIN, Ronald. Taking rights seriously. Cambridge: Harvard University Press, 1977.

${ }^{21}$ BALKIN, Jack M. Constitutional redemption: political faith in an unjust world. Cambridge: Harvard University Press, 2011. p. 8-16. 


\section{CONSIDERAÇõES FinAIS}

O Direito, tendo em conta a Constituição da República e a jurisdição constitucional, se observado adequadamente e com deferência aos demais Poderes, presente a harmonia, não representa ameaça à democracia. Preserva-se a fronteira entre uns e outros e concilia-se autogoverno e limitação de poder.

A atividade desenvolvida na academia, em especial na Faculdade Nacional de Direito, é central na integração do Direito à democracia, no que auxilia o jurista na solução de controvérsias sem interferir indevidamente nos Poderes eleitos. Ao mesmo tempo, contribui para a perpetuação dos valores emanados da Constituição de 1988, a refletir a luta da sociedade civil pela concretização dos direitos humanos e da democracia.

\section{REFERÊNCIAS BIBLIOGRÁFICAS:}

BALKIN, Jack M. Constitutional redemption: political faith in an unjust world. Cambridge: Harvard University Press, 2011.

BARROSO, Luís Roberto (Org.). A reconstrução democrática do direito público no Brasil. Rio de Janeiro: Renovar, 2007.

BICKEL, Alexander M. The least dangerous branch: the Supreme Court at the bar 490 of politics. Indianapolis: Bobbs-Merrill, 1962.

DAHL, Robert. On democracy. New Haven: Yale University Press, 1996.

DWORKIN, Ronald. Taking rights seriously. Cambridge: Harvard University Press, 1977.

ELSTER, Jon. Ulysses and the sirens. Cambridge: Cambridge University Press, 1979.

FERES JÚNIOR, João; CAMPOS, Luiz Augusto; DAFLON, Verônica Toste; VENTURINI, Anna Carolina. Ação afirmativa: conceito, história e debates. Rio de Janeiro: EdUerj, 2018.

HABERMAS, Jürgen. Direito e democracia: entre facticidade e validade. Tradução de Flávio Siebeneichler. Rio de Janeiro: Tempo Brasileiro, v. 1, 1997. 
LOPES, Eduardo Lasmar Prado. Um esboço das biografias no Brasil: a liberdade de expressão, a personalidade e a Constituição de 1988. São Paulo: Almedina, 2015.

MIRANDA, Jorge. Teoria do estado e da constituição. Rio de Janeiro: Forense, 2003.

SAGER, Lawrence G. Justice in plainclothes: a theory of American constitutional practice. New Haven: Yale University Press, 2004.

SARMENTO, Daniel. Direito adquirido, emenda constitucional, democracia e justiça social. Revista Eletrônica sobre a Reforma do Estado (RERE), Salvador, Instituto Brasileiro de Direito Público, n. 12, p. 1-28, dez./jan./fev. 2008. Disponível em: http://www.direitodoestado.com.br/codrevista.asp?cod=248. Acesso em: 5 jul. 2021.

SCHREIBER, Simone. Liberdade de expressão: justificativa teórica e a doutrina da posição preferencial no ordenamento jurídico. In: BARROSO, Luís Roberto (Org.). A reconstrução democrática do direito público no Brasil. Rio de Janeiro:

Renovar, 2007.

SOUZA NETO, Cláudio Pereira de; SARMENTO, Daniel. Notas sobre jurisdição constitucional e democracia: a questão da "última palavra" e alguns parâmetros de autocontenção judicial. Quaestio Iuris, v. 6, n. 2, p. 119-161, 2013.

TILLY, Charles. Democracy. New York: Cambridge University Press, 2007. 